\title{
Primer registro de Nabis paranensis Harris, 1931 (Heteroptera: Nabidae) para la provincia de Catamarca, Argentina
}

\author{
First record of Nabis paranensis Harris, 1931 (Heteroptera: Nabidae) \\ for the Catamarca Province, Argentina
}

Eduardo I. Faúndez $z^{1,2}$

\section{RESUMEN}

Se entrega el primer registro para Nabis paranensis Harris, 1931 para la provincia de Catamarca, Argentina, y se comenta la importancia de los registros de esta especie en el oeste del país.

Palabras clave: Heteroptera, Nabidae, new record, Argentina.

\begin{abstract}
The first records of Nabis paranensis Harris, 1931 for the Argentinean province of Catamarca are provided. The importance of the records of this species in the western part of the country is commented.

Key words: Heteroptera, Nabidae, new record, Argentina.
\end{abstract}

Nabidae es una familia de insectos heterópteros que cuenta con cerca de 500 especies distribuidas en 20 géneros (Schuh \& Slater 1995). Los nábidos son insectos predadores, caracterizados por sus patas protorácicas adaptadas para cazar y manejar presas (Schuh \& Slater 1995). Por esta razón es que las especies de esta familia son ampliamente usadas como controladores de plagas (Braman 2000); adicionalmente también son de interés por su capacidad de picar a seres humanos de forma adventicia (Faúndez \& Carvajal 2011).

En Argentina esta familia ha sido revisada recientemente y se encuentra representada por 14 especies clasificadas en cinco géneros (Cornelis \& Coscarón 2013); sin embargo, para algunas especies aún existen pocos registros, especialmente en las zonas áridas del noroeste del país.

Nabis paranensis Harris, 1931 (Figuras 1, 2) es un nábido poco conocido, miembro del complejo de especies de Nabis punctipennis Blanchard, 1852; el que actualmente contiene cinco especies distribuidas en Argentina, sur de Brasil, Chile y Uruguay (Faúndez \& Carvajal 2014). N. paranensis se conoce de Paraná, Brasil, y en Argentina ha sido citado para las provincias Buenos Aires, Jujuy, La Pampa y Misiones. A continuación entregamos los primeros registros para la provincia de Catamarca:

Material examinado: Catamarca, $10 \mathrm{~km} \mathrm{NE}$ La Merced, 775 m s.n.m. $28^{\circ} 04^{\prime}$ 'S-65 36'W, 5- III2006, D. A. Rider leg. (D. A. Rider Coll.), $1{ }^{\top} 2$ 우우.

Comentarios: Los registros para esta especie en el Oeste de Argentina son escasos, pero al mismo tiempo interesantes, ya que $N$. paranensis pareciera ser cercana a Nabis ashworthi Faúndez \& Carvajal 2014 de la cual podría haberse separado con el levantamiento de la cordillera de los Andes. De este modo registros como el presentado en esta contribución ayudan a comprender mejor la posible relación entre ambas especies y refuerzan esta teoría. Es necesario estudiar la biología de $N$. paranensis, tanto para conocer sus estados inmaduros, como también para saber y evaluar su desempeño como supresor de las poblaciones de plagas agrícolas en los lugares donde se distribuye, ya que como especie nativa puede representar una buena opción de control biológico.

\footnotetext{
Entomology Department, North Dakota State University, Dept. 7650, P.O. Box 6050; Fargo, ND. USA.

2 Departamento de Zoología Médica, Centro de Estudios en Biodiversidad (CEBCh), Magallanes Nº 1979, Osorno, Chile.

* Autor por correspondencia: eduardo.faundez@ndsu.edu
} 


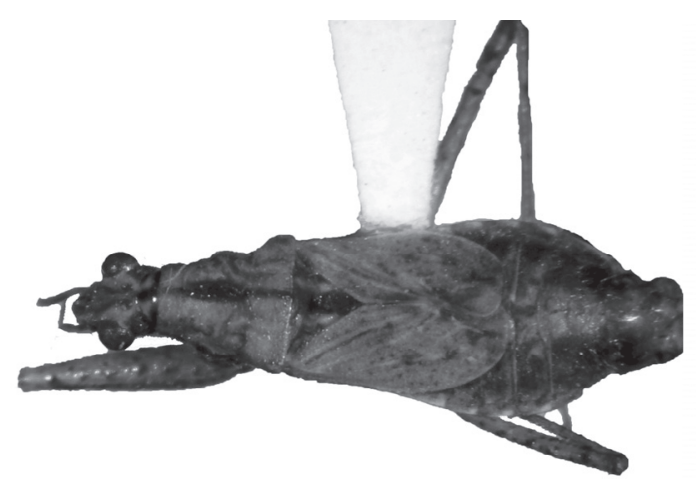

Figura 1. Nabis paranensis, vista dorsal, macho.

\section{Agradecimientos}

Deseamos agradecer a David A. Rider (North Dakota State University) por permitirnos acceso al

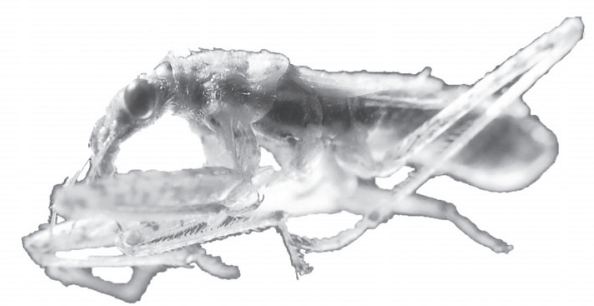

Figura 2. Nabis paranensis, vista lateral, macho.

material estudiado en este trabajo, y a María del C. Coscarón (Universidad Nacional de La Plata), por atender nuestras consultas.

\section{Literatura Citada}

Braman, S. K.

2000. Damsel bugs (Nabidae). In: Schaefer C. W. \& Panizzi A. R. (eds.): Heteroptera of Economic Importance. CRC Press, Boca Raton, Pp. 639-656.

Cornelis, M.; Coscarón, M.C.

2013. The Nabidae (Insecta, Hemiptera, Heteroptera) of Argentina. Zookeys, 333: 1-30.

Faúndez, E.I.; Carvajal, M.A.

2011. A human case of bitting by Nabis punctipennis (Hemíptera: Heteroptera: Nabidae) in Chile. Acta Entomologica Musei Nationalis Pragae, 51(2): 407-409.
Faúndez, E.I.; Carvajal, M.A.

2014. Contribución al conocimiento de las especies del complejo de Nabis punctipennis Blanchard, 1852 (Hemiptera: Heteroptera: Nabidae) en Chile. Anales del Instituto de la Patagonia, 42 (1): 63-69.

Schuh, R.T.; Slater, J.A.

1995. True bugs of the World (Hemiptera: Heteroptera). Classification and natural history. Cornell University Press, New York, 336 pp. 